\title{
Interactive Computer Aided Learning and Teaching of Analytical Mechanics
}

\author{
http://dx.doi.org/ijep.v1i3.1788 \\ A. Aan, M. Heinloo and E. Aarend \\ Estonian University of Life Sciences, Tartu, Estonia
}

\begin{abstract}
The aim of this paper is to introduce a new possibility for learning Analytical Mechanics via internet. This subject belongs to the field of engineering, the theoretical parts of lecture materials are available online in PDF format and have special links to switch on the interactive examples on the worksheets of the Computer Package Mathcad.
\end{abstract}

Index Terms - computer aided engineering, interactivity, attractiveness, internet, analytical mechanics, Computer Package Mathcad.

\section{INTRODUCTION}

The digital age has transformed education, both formally in the classroom and permanently in any other environment. Although there are many types of interactive materials that have been used in learning for decades, in most cases interactive learning materials are thought of as those that are done on a computer. Many of these materials are made available over the internet, although some are distributed in the form of software [1].

Interactive learning is most commonly defined into three distinct types. These learning types are grouped based on the types of interaction in which they engage students. The first, learner-content, is a type of teaching where the student interacts solely with the facts, readings and information. In the second style, learner-instructor, the primary interaction is with the instructor. The third style is called learner-learner, and this is where the student primarily interacts with his peers to learn new material [2, 3].

U.S. Department of Education report 2009 showed that the most effective interactive learning occurs when all three types of interaction are used [2].

Interactive learning is the counterpart of lecture-type learning. It is the active learning process as opposite to the passive system of a lecture-type. In interactive learning, the students use tangible objects to acquire information. Teachers do not directly pass the information to them. Students acquire the information themselves by allowing them to discover it. Of course, guidance by teachers is necessary. They still provide initial information to the students [4].

In interactive environment students are engaged with the materials rather than simply memorizing the information, the learning is deeper and more lasting. With more engagement student spent more time on the learning task [2]. In interactive learning materials student is in control of the progress of the lesson to some degree. This means in individual learning the learner can make his own pace and studying style of him. In many schools and universities the teachers have lack of time and are unable to give dedicated attention to individual students for very long.
Interactive materials can help provide learning experience without the need for continuous teacher intervention [1].

Engineering teaching material has to be attractive and interactive to make students research technical problems. Attractive learning material means that it is visualized by using many schemes, figures, and animations. Students will understand learning materials better if they can actively engage in the examples of problem-solving via computer screen and change relevant parameters, equations, and simulate the motions. These are hands-on learning materials on the computer. The students can approach to attain information through hands-on interactive experience by using the computer.

There are articles available about interactive learning opportunities in other subjects. For example, Maxima Software - a tool for developing online applications intended for interactive solutions of the examples in Control Theory by K. Zakova [5]. The advantages of the Maxima software include its online availability via internet for all interested users any time, and it can be used locally on the desktop computer or in the notebook. For all technical universities devoted to electrical engineering can use Maxima for computations like useful instrument in an educational process mainly in online and distance forms of education [5]. Also in mathematics we can find interactive learning materials. Heinloo [6] and Talman [7] have made e-courses of mathematics that are interactive and visualized with figures and animations. Heinloo [6] used interactive Mathcad worksheets for lecture notes, examples and exercises. Also there are the links to the video clips, which provide a student with an opportunity to watch and review the example problem solutions at home.

From internet we can find lot of interactive learning materials for different subjects [8, 9, 10].

This paper introduces interactive learning materials on Analytical Mechanics, composed in the Institute of Technology of Estonian University of Life Sciences in Estonian language [11]. These interactive materials are mostly learner-instructor type, but on the computer and over the internet they are also considered learner-content learning material.

\section{MATERIALS AND METHODS}

Main text of interactive learning materials have been composed by the program Microsoft Word [12] and converted to PDF (Portable Document Format) [13] format. In PDF format all the linked citations work normally as defined. The figures have been composed by using program Adobe Illustrator [14] with occasional addition of pictures. Interactive examples have been composed on the worksheets of the Computer Package Mathcad. Main text 
PAPER

INTERACTIVE COMPUTER Aided LEARNING AND TEACHING OF ANALYTICAL MECHANICS

in PDF and Mathcad files are connected with links and are available in Estonian e-Learning Development Centre repository [15].

\section{ON VISUALIZATION OF LEARNING MATERIAL}

Colorful and, where possible, lifelike figures are used to make the material more attractive for students (Fig. 1). Some of examples in the learning materials are visualized by video clips, for example [16].

\section{INTERACTIVE LEARNING MATERIAL}

If the learning materials are on the computer, student can use program features like search, zoom, copy, etc. that accentuate their interactivity.

In terms of collaboration with other computer program features, it is possible to make learning material more interactive by using inside the text links to citations or equation numbers. This gives an opportunity to move inside the text and switch between linked parts on different pages.

Fig. 2 shows a part of the contents of learning material [18] where clicking on the word "Näide 2.6" leads to the page with the solution of the example 2.6

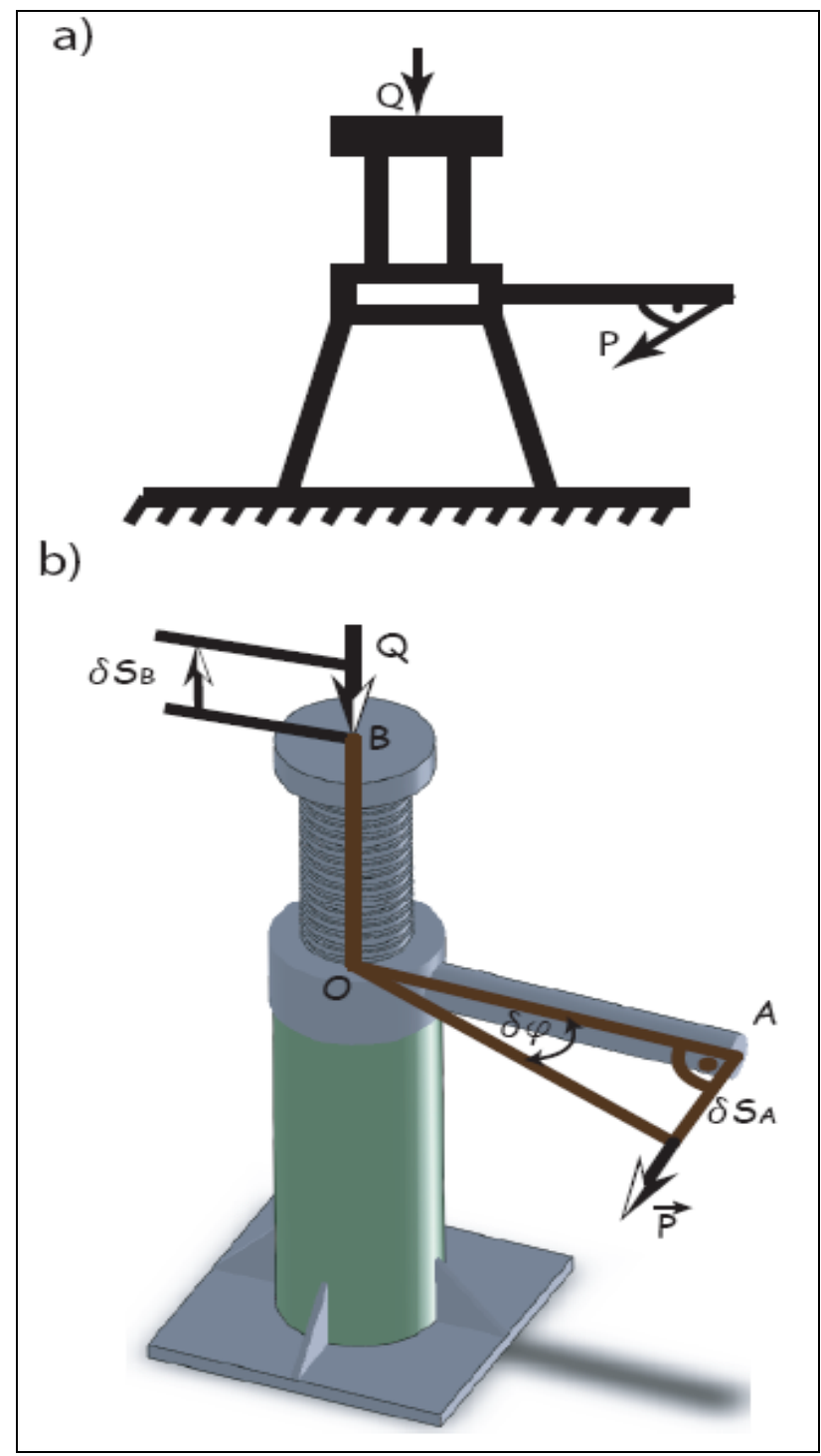

Figure 1. Comparison of traditional (a) [17] and lifelike (b) [18] screw jack calculation figure
In Fig. 3 we can see an example (Näide 2.6), where mass $\mathrm{A}$ is connected with cylinder $\mathrm{B}$ over wheel $\mathrm{O}$ by rope. Cylinder $\mathrm{B}$ is moving down and pulling mass $\mathrm{A}$ downwards. At the same time cylinder B is spinning off the rope. The question is - what is the acceleration of point C.

In the problem solution (Fig. 4) we can see that one of the equations that has been used is Lagrange equations (Lagrange $i$ vorrrandid) and in the main text it is equation 2.40. Clicking on equation number leads to the explanation (Fig. 5) of the Lagrange equations (Lagrange võrrandid) in the main text.

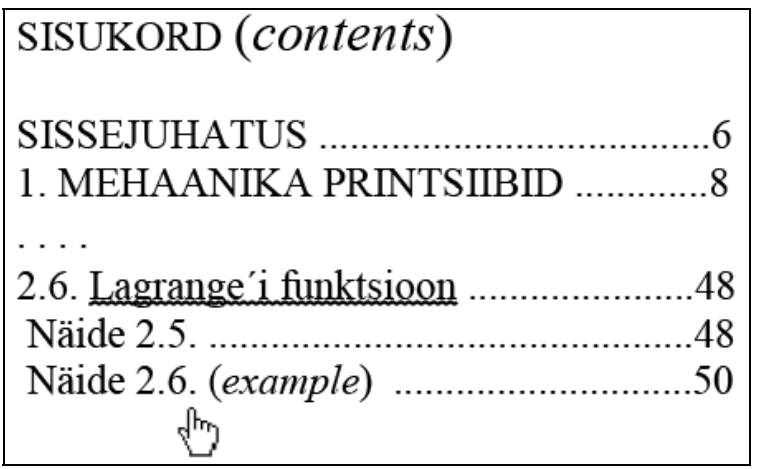

Figure 2. Links in the contents

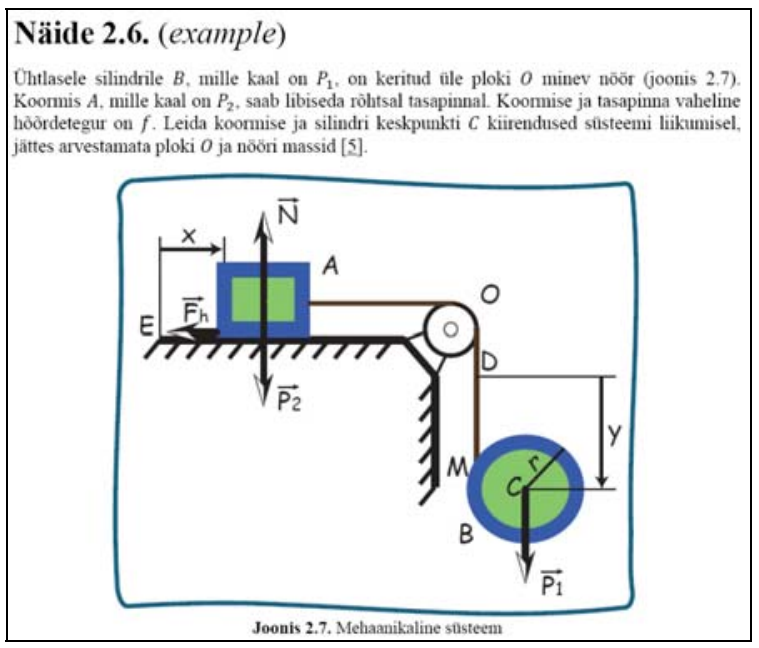

Figure 3. The mechanical system in the example

\section{Lahendus (solution)}

Süsteemil on kaks vabadusastet. Valime üldistatud koordinaatideks koormise $A$ kauguse $x$ tasapinna mingist punktist $E$ ja silindri tsentri kauguse $y$ nööri mingist punktist $D \quad\left(q_{1}=x, q_{2}=y\right)$. Antud süsteemi Lagrange'i võrranditeks (equation $\underline{2.40}$ ) on

$$
\frac{d}{d t}\left(\frac{\partial T}{\partial \dot{q}_{1}}\right)-\frac{\partial T}{\partial q_{1}}=Q_{1} \text {, }
$$

Figure 4. A part of solution of the example problem 
PAPER

INTERACTIVE COMPUTER Aided LEARNING AND TEACHING OF ANALYTICAL MECHANICS

If a student wishes to learn more about Lagrange equations, he or she will be directed to corresponding literature by clicking on the citation (Fig. 6).

If the literature is available on the internet, the student can continue from there by using relevant internet addresses. The name of the book can be connected with links to library internet catalog. In Estonia there is library ecatalog Ester that shows the quantity and availability of books in library [19].

Let us consider an interactive example about physical pendulum on Mathcad [20] worksheet to which leads a special link in the main text (Fig. 7).

\begin{tabular}{|l} 
Lagrange teist tüüpi võrrandeid on $k$ tükki, \\
st sama palju kui on süsteemil \\
vabadusastmeid $[\underline{3}, \underline{5}, \underline{6}]$ \\
$\frac{d}{d t}\left(\frac{\partial T}{\partial q_{1}}\right)-\frac{\partial T}{\partial q_{1}}=Q_{1}$ \\
$\frac{d}{d t}\left(\frac{\partial T}{\partial q_{2}}\right)-\frac{\partial T}{\partial q_{2}}=Q_{2}$ \\
$\frac{d}{d t}\left(\frac{\partial T}{\partial q_{k}}\right)-\frac{\partial T}{\partial q_{k}}=Q_{k}$
\end{tabular}

Lagrange teist tüüpi võrrandite arv on minimaalne, mis on vajalik süsteemi liikumise määramiseks. Lagrange teist tüüpi ... .

Figure 5. A part in main text with Lagrange equations

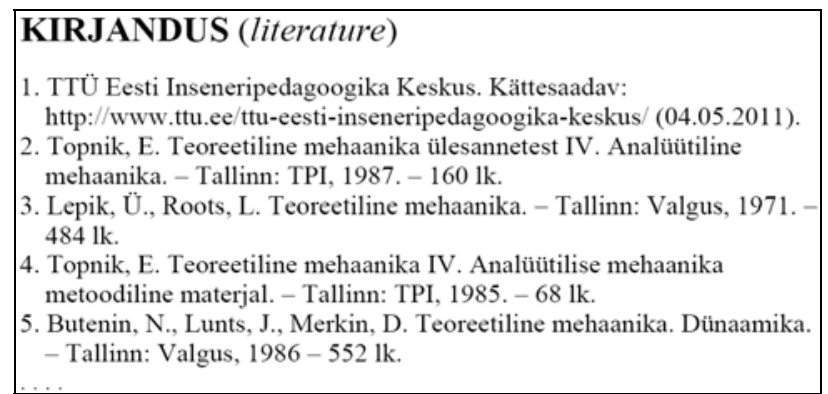

Figure 6. Literature from main text

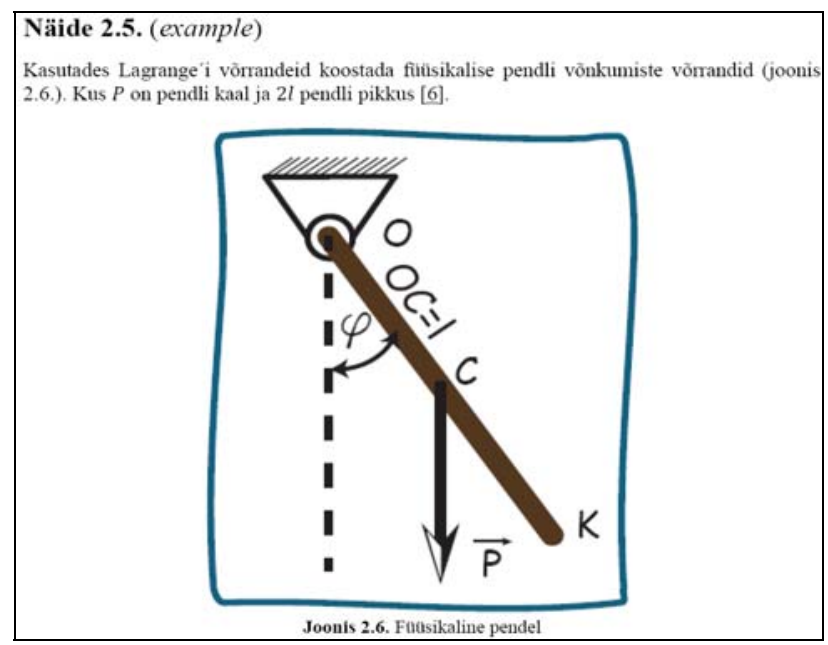

Figure 7. A physical pendulum in the example
Fig. 8 shows the first possible derivation of the equations of motion of physical pendulum in the main text.

Fig. 9 shows the second possible derivation of the equations of motion of physical pendulum, and the link leading to the interactive example on the worksheet of Mathcad.

On Mathcad worksheet a learner can visualize the motion of pendulum by graphs (Fig. 10). A learner can also change the values of inclination angle $\varphi$ and angular velocity $\varphi^{\prime}$ at the initial moment $\mathrm{t}=0$ and observe what happens on figures.

On the worksheet of Mathcad a learner can use controls like slider to define the parameters of pendulum. Fig. 11 shows the slider, defining the length of the pendulum.

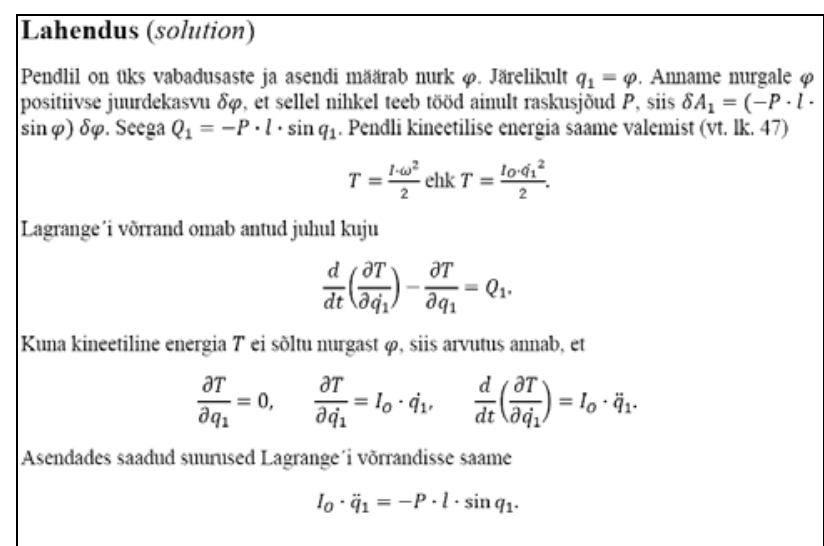

Figure 8. Derivation of equation of motion for a physical pendulum

Kuna jòtud $P$ on potentsiaalne, võib kasutada ka vorrrandeid (2.44). Suunates z-telje vertikaalselt ïles, saame potentsiaalseks energiaks $\Pi=P_{z}=-P \cdot l \cdot \cos \varphi$. Kasutades Lagrange i funktsiooni (2.42)

$$
L=\frac{I_{0} \cdot \dot{q}_{1}^{2}}{2}-P \cdot l \cdot \cos q_{1} .
$$

Leiame osatuletised

$$
\frac{\partial L}{\partial q_{1}}=-P \cdot l \cdot \sin q_{1}, \quad \frac{\partial L}{\partial \dot{q}_{1}}=I_{0} \cdot \dot{q}_{1}, \quad \frac{d}{d t}\left(\frac{\partial L}{\partial \dot{q}_{1}}\right)=I_{0} \cdot \ddot{q}_{1} .
$$

Asetades tulemused Lagrange' i vòrrandisse, saame sama tulemuse, mis eelnevalt

$$
I_{0} \cdot \ddot{q}_{1}+P \cdot l \cdot \sin q_{1}=0 .
$$

Mathcadi interaktiivne näide. (Mathcad interactive example)

Figure 9. Link to Mathcad interactive example [21]

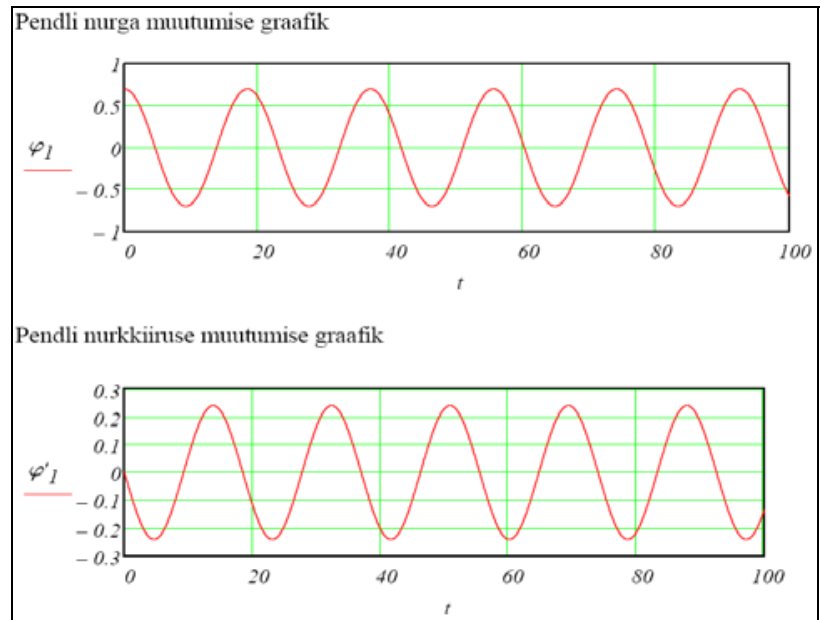

Figure 10. Pendulum angle (upper) and angular velocity (lower) change 
PAPER

Frames in Fig. 12 from [22] visualize the motion of a double pendulum determined by their equations of motion.

It is possible to hide equations and arguments on the worksheet of Mathcad. This gives a possibility to provide interactive sheets with controls only. In Fig. 13 there are the sliders to change the pendulum's mass and length. To change the initial angles of the pendulums we can use radio buttons on the worksheet of Mathcad (Fig. 13) and then visualize the motion of a double pendulum on the figure.

\section{CONCLUSION}

This paper presented opportunities to make learning materials more attractive and interactive using examples from subject analytical mechanics in Estonian University of Life Sciences.

The learning material has been made attractive and interactive by using different computer programs and internet.

\section{REFERENCES}

[1] S. Smith, What are interactive learning materials? Available at: http://www.ehow.com/info_7947754_interactive-learningmaterials.html

[2] L. Brogan, Interactive Learning Definition, Available at: http://www.ehow.com/about 5494900 interactive-learningdefinition.html, Date accessed: 20.06.2011.

[3] A. Stovall, Definition of Interactive Learning Content, Available at: http://www.ehow.com/about 6727386 definition-interactivelearning-content.html, Date accessed: 20.06.2011.

[4] K. Chapman, What is Interactive Learning, Available at: http://www.howtodothings.com/education/what-is-interactivelearning, Date accessed: 15.06.2011.

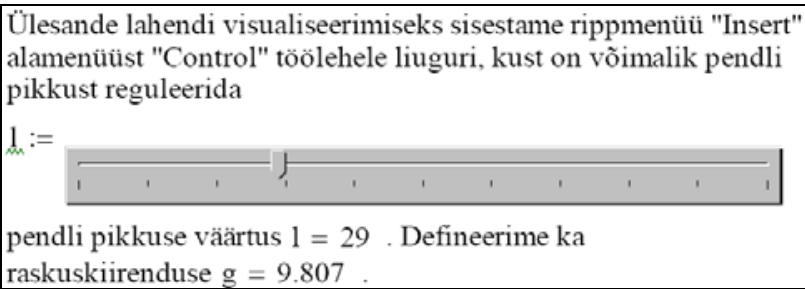

Figure 11. A Slider on the worksheet of Mathcad, defining a pendulum length

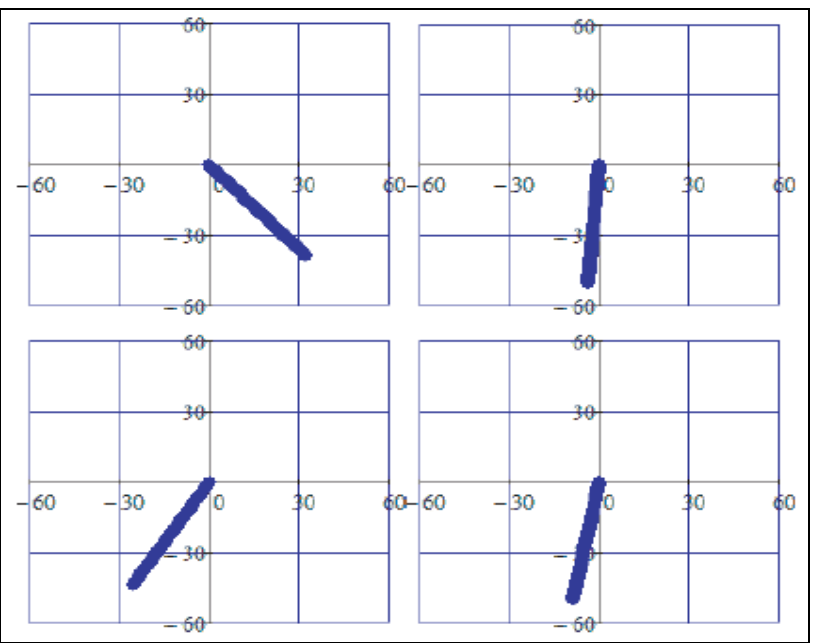

Figure 12. Frames from animated pendulum move
[5] K. Zakova, Maxima - An Open Alternative for Engineering Education. International Journal of Engineering Pedagogy (iJEP), North America, 1, apr. 2011. Available at: http://onlinejournals.org/index.php/i-jep/article/view/1598. Date accessed: 14.06. 2011.

[6] M. Heinloo, T. Tärgla, Visuaalne e-matemaatika (in estonian), Available at: http://deepthought.ttu.ee/aa/artiklid/497.pdf. Date accessed: 15.06.2011.

[7] L. A. Talman, Mathematics animated, Available at: http://clem.mscd.edu/ talmanl/MathAnim.html, Date accessed: 15.06.2011.

[8] Teacher Tap, Available at: http://eduscapes.com/tap/index.htm, Date accessed: 20.06.2011.

[9] Active Math http://demo.activemath.org/ActiveMath2/main/ menu.cmd, Date accessed: 20.06.2011.

[10] Füüsika koolitarkus, Available at: http://www.fyysika.ee/opik/ index.php?tase $=$ sisu\&pid=17\&nom $=0$, Date accessed: 20.06.2011.

[11] Estonian University of Life Sciences, Available at: http://www.emu.ee/en/, Date accessed: 20.06.2011.

[12] Microsoft Office, Word, http://office.microsoft.com/en-gb/word/, Date accessed: 09.05.2011.

[13] Adobe PDF http://www.adobe.com/products/acrobat/adobepdf.html, Date accessed: 10.06.2011.

[14] Adobe Illustrator, http://www.adobe.com/products/illustrator.html, Date accessed: 10.06.2011.

[15] Estonian e-Learning Development Centre, Repository, Available at: http://www.e-ope.ee/repositoorium/otsing?@=6tsk\#euni repos tory_10895, Date accessed: 09.06.2011.

[16] Double pendulum, Available at: http://www.youtube.com/user/ TheoreticalMechanics\#p/a/u/1/6BHYuJwPw8I, Date accessed: 09.08.2011.

[17] Ü. Lepik, L. Roots, Teoreetiline mehaanika (in Estonian). Tallinn: Valgus, 1971

[18] A. Aan, M. Heinloo, E. Aarend, Interactive analytical mechanics, Available at: http://www.e-ope.ee/ download/euni repository/file/ 1592/Anal\%C3\%BC\%C3\%BCtilise\%20mehaanika\%20konspekt. pdf, Date accessed: 07.06.2011.

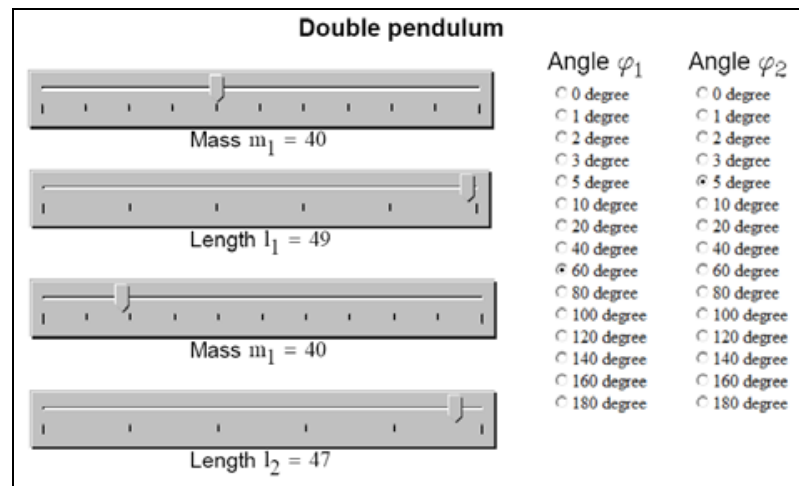

B.

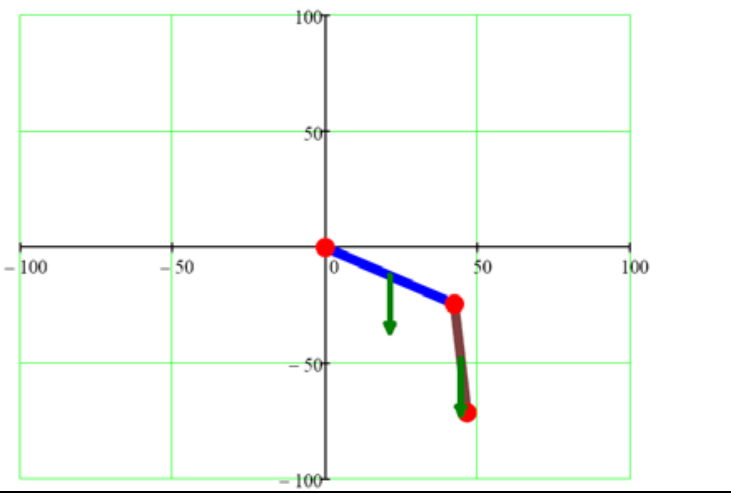

Figure 13. Slider and radio button controlled double pendulum [23] 
PAPER

INTERACTIVE COMPUTER AIDED LEARNING AND TEACHING OF ANALYTICAL MECHANICS

[19] E-catalog for Tartu libraries, Available at: http://tartu.ester.ee/search, Date accessed: 10.06.2011.

[20] PTC Mathcad, Available at: http://www.ptc.com/products/ mathcad/index-v2.htm, Date accessed: 10.06.2011.

[21] A. Aan, M. Heinloo, Näide 4.1, Available at: http://www.eope.ee/_download/euni_repository/file/1592/N\%C3\%A4ide\%204. 1.xmcd?download=true, Date accessed: 10.06 .2011 .

[22] A. Aan, Pendulum, Available at: http://www.youtube.com/ watch?v=Ag2MU5tMXj4, Date accessed: 11.06.2011.

[23] A. Aan, M. Heinloo, Double Pendulum, Available at: http://www.e-ope.ee/ download/euni repository/file/1592/Double \%20pendulum.xmcd?download=trueAuthors, Date accessed: 22.06.2011.
AUTHORS

A. Aan is with the Institute of Technology, Estonian University of Life Sciences, Kreutzwaldi 64, 51014, Tartu, Estonia (e-mail: aare.aan@emu.ee).

M. Heinloo is with the Institute of Technology, Estonian University of Life Sciences, Kreutzwaldi 64, 51014, Tartu, Estonia (e-mail: mati.heinloo@emu.ee).

E. Aarend is with the Institute of Technology, Estonian University of Life Sciences, Kreutzwaldi 64, 51014, Tartu, Estonia (e-mail: dmmd@emu.ee).

Received 31 August 2011. Published as resubmitted by the authors 26 September 2011. 